\title{
Aspectos epidemiológicos, clínicos e terapêuticos da COVID-19
}

\section{Epidemiological, clinical and therapeutic aspects of COVID-19}

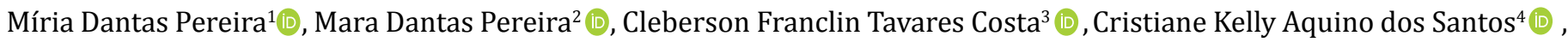 \\ Estélio Henrique Martin Dantas ${ }^{5,6}$ (B)
}

1. Graduada em Farmácia pela Universidade Tiradentes ( UNIT), Aracaju/SE, Brasil. 2. Graduada em Psicologia pela Universidade Tiradentes (UNIT), Aracaju, SE, Brasil. 3. Doutor pelo Programa de Pós-graduação Stricto Sensu em Saúde e Ambiente da Universidade Tiradentes (UNIT), Aracaju, SE, Brasil. 4. Mestre pelo Programa de Pós-graduação Stricto Sensu em Educação Física da Universidade Federal de Sergipe (UFS), Aracaju, SE, Brasil. 5. Docente no Programa de Pós-graduação Stricto Sensu em Saúde e Ambiente (PSA) da Universidade Tiradentes (UNIT), Aracaju, SE, Brasil. 6. Docente no Programa de Pós-graduação Stricto Sensu em Enfermagem e Biociências da Universidade Federal do Estado do Rio de Janeiro (UNIRIO), Rio de Janeiro, RJ, Brasil.

\section{Resumo}

Objetivo: apresentar os aspectos epidemiológicos, clínicos e terapêuticos da COVID-19. Método: trata-se de uma revisão narrativa da literatura, realizada por meio da busca por publicações científicas indexadas nas bases de dados: PubMed, Europe PMC, ScienceDirect e SciELO. Os seguintes descritores foram utilizados: "COVID-19", "diagnosis", "drug therapy", "pandemics" e "SARS-CoV-2". Ao final, foram selecionadas 32 publicações. Resultados: a análise dos estudos evidenciou que a rápida disseminação da COVID-19 pode estar relacionada à forma de transmissão, bem como à capacidade de o vírus permanecer estável em aerossóis e superfícies contaminadas. 0 diagnóstico de COVID-19 tem sido realizado mediante observação dos sintomas, e por um método de biologia molecular. Ainda não há medicamentos específicos e uma vacina contra a doença. No entanto, alguns medicamentos existentes no mercado, indicados para tratar outras patologias, estão sendo considerados como promissoras terapêuticas para a doença. Conclusão: a pandemia de COVID-19 já se configura como o maior desafio para saúde pública do século XXI, com elevadas taxas de morbidade e mortalidade em todo o mundo, principalmente devido à alta infectividade, e à severidade das manifestações clínicas em populações de risco, sendo mais letal. A falta de evidências científicas conclusivas quanto à eficácia e à segurança dos medicamentos off label no tratamento da doença tem gerado incertezas nos procedimentos de decisão clínica, sendo primordial a realização de ensaios clínicos randomizados, envolvendo um maior número de pacientes.

Palavras-chave: COVID-19. Diagnóstico. Pandemias. SARS-CoV-2. Tratamento Farmacológico.

\begin{abstract}
Objective: to present the epidemiological, clinical and therapeutic aspects of COVID-19. Method: this is a narrative review of the literature, performed through the search of scientific publications indexed in the databases: PubMed, Europe PMC, ScienceDirect and SciELO. The following descriptors were used: "COVID-19", "diagnosis", "drug therapy", "pandemics" and "SARS-CoV-2". At the end, 32 publications were selected. Results: the analysis of the studies showed that the rapid spread of COVID-19 may be related to the form of transmission, as well as to the ability of the virus to remain stable in aerosols and contaminated surfaces. The diagnosis of COVID-19 has been made through observation of symptoms, and by a molecular biology method. There are still no specific drugs and a vaccine against the disease. However, some drugs on the market, indicated to treat other pathologies, are being considered as promising therapeutics for the disease. Conclusion: the COVID-19 pandemic is already configured as the greatest public health challenge of the 21st century, with high morbidity and mortality rates worldwide, mainly due to high infectivity, and severity of clinical manifestations in populations at risk, being more lethal. The lack of conclusive scientific evidence regarding the efficacy and safety of off-label medications in the treatment of the disease, has generated uncertainties in clinical decision-making procedures, and it is essential to carry out randomized clinical trials, involving a greater number of patients.
\end{abstract}

Keywords: COVID-19. Diagnosis. Pandemics. Sars-Cov-2. Drug Therapy.

\section{INTRODUÇÃO}

Em 31 de dezembro de 2019, foi notificado à Organização Mundial da Saúde (OMS) a ocorrência de um surto de pneumonia na cidade de Wuhan, província de Hubei, China. Rapidamente, o patógeno foi identificado e denominado de Coronavírus da Síndrome Respiratória Aguda Grave 2 (SARS-CoV-2). Este vírus causa a Doença de Coronavírus 2019 (COVID-19) ${ }^{1,2}$.

No início de janeiro 2020, foi realizado o sequenciamento genômico e filogenético do SARS-CoV-2, e constatou-se que se trata de um betacoronavirus, do mesmo subgênero do Coronavírus da Síndrome da Insuficiência Respiratória Aguda Grave (SARS-CoV), que causou uma epidemia na China em 2002, e o Coronavírus da Síndrome Respiratória do Médio Oriente (MERS-CoV), que ocasionou o mesmo quadro no Oriente Médio em $2012^{3}$.

Em relação à contagem de casos e óbitos de COVID-19, até a presente data, 16.6.2020, o mundo apresenta 7.941.791 de 
casos confirmados e 434.796 óbitos. No Brasil, na mesma data, 867.624 casos foram confirmados e 43.332 óbitos notificados, de acordo com dados divulgados pela $\mathrm{OMS}^{4}$.

Em geral, a COVID-19 é transmitida, principalmente, através de gotículas respiratórias, aerossóis e da mucosa nasal, oral e conjuntiva de pacientes infectados ${ }^{4}$. A sintomatologia da doença é semelhante à de outras viroses respiratórias, podendo apresentar sintomas como febre, tosse, geralmente seca, cansaço e, em casos mais graves (5\%), dispneia, sangramento pulmonar e insuficiência renal ${ }^{3}$.

A taxa de letalidade da COVID-19 varia, principalmente, segundo a faixa etária e as condições clínicas associadas ${ }^{5}$. Em contrapartida, como medidas de combate à disseminação da doença, preconiza-se lavar as mãos frequentemente, evitar contato direto e adotar medidas de distanciamento social, como a quarentena ${ }^{6}$.

Neste cenário de calamidade, cabe ressaltar que grandes esforços em nível mundial têm sido feitos entre profissionais da saúde e pesquisadores, por meio das buscas por maior entendimento clínico da doença, e mais rápidos e precisos métodos de diagnóstico, sobretudo, um tratamento farmacológico específico e imunoprevenção (vacina)7. Considerando o exposto, o objetivo do presente estudo é apresentar os aspectos epidemiológicos, clínicos e terapêuticos da COVID-19.

\section{MÉTODOS}

Trata-se de uma Revisão Narrativa da Literatura (RNL), realizada no período de abril a junho de 2020. De acordo com Lugoboni e Colaboradores ${ }^{8}$, a RNL é uma interpretação geral das mais relevantes pesquisas que utilizaram métodos explícitos e reproduzíveis, sendo indicada para descrever e discutir o desenvolvimento de um dado assunto, sob ponto de vista teórico ou contextual. Neste sentido, uma RNL sobre a pandemia de COVID-19, pode possibilitar uma ampla reflexão sobre o tema, especialmente, por se tratar de uma problemática emergente, que requer resposta rápida e efetiva.

Para a elaboração do estudo, utilizou-se a seguinte questão norteadora: "Quais são os principais estudos que abordam os aspectos epidemiológicos, clínicos e terapêuticos da COVID-19?". As buscas por publicações científicas foram realizadas durante os meses de abril e maio de 2020, por meio de consultas nas bases de dados National Library of Medicine (PubMed), Europe PubMed Central (Europe PMC), ScienceDirect e Biblioteca Virtual de Saúde (BVS). Foram utilizados os Descritores em Ciências da Saúde (DeCS) e as do Medical Subject Headings (MeSH Terms): "COVID-19", "Diagnosis", "Drug Therapy", "Pandemics", "SARS-CoV-2", empregados em cruzamento com os operadores booleanos "AND" e "OR".

Utilizou-se o gestor de referências bibliográficas Zotero versão 5.0, como ferramenta para auxiliar na seleção dos estudos e na condução da RNL. Como critérios de inclusão, optou-se pela inclusão de artigos científicos, editoriais, comunicações de profissionais da área da saúde, protocolos clínicos e manuais, publicados nos idiomas (português, espanhol, inglês e francês), nas quatro bases de dados delimitadas, apenas no ano de 2020. Em relação aos critérios de exclusão, estabeleceu-se a eliminação de estudos duplicados e publicados anteriores ao ano de 2020.

Para minimizar possível viés de seleção dos estudos, como erro de interpretação dos artigos analisados, dois autores independentes (MIDP e MADP) efetuaram a avaliação crítica, a extração e a síntese dos dados. De início, chegou-se a um total de $(n=5.436)$ publicações. Depois de eliminar $(n=1.051)$ publicações por serem duplicadas, foram incluídos um total de $(n=4.385)$ para leitura de título e resumo. Desse total, $(n=3.636)$ estudos foram excluídos por não atenderem aos critérios de elegibilidade. Em seguida, foram analisadas, na íntegra, $(n=749)$ publicações, das quais $(n=717)$ foram excluídas por não apresentarem clareza, coerência conceitual e relevância temática. Ao final da análise, um total de $(n=32)$ estudos preencheu os critérios de inclusão, e foi selecionado para o desenvolvimento da revisão. A esquematização da seleção das publicações elegíveis está reproduzida em forma de fluxograma (figura 1).

Figura 1. Fluxograma do processo de identificação e inclusão dos estudos.

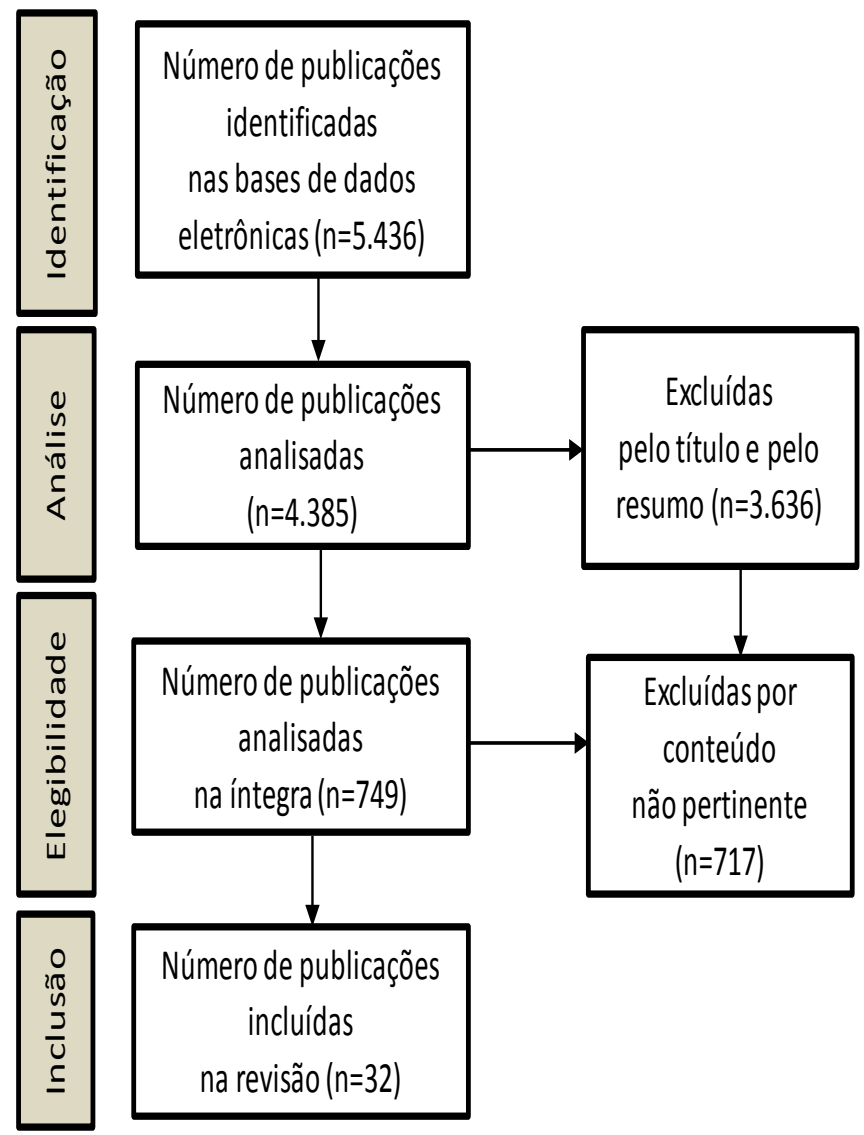

Fonte: Autoria própria. 


\section{RESULTADOS E DISCUSSÃO}

\section{Origem}

Os Coronavírus (CoVs) são vírus de origem zoonótica, descritos, pela primeira vez, em 1966 por Tyrell e Bynoe. Entre os vários CoVs patogênicos humanos, a maioria está associada a condições clínicas leves, com duas exceções notáveis: o SARSCoV e MERS-CoV ${ }^{9,10}$.

Em novembro de 2002, um novo betacoronavírus surgiu em Guangdong, sul da China, e resultou em mais de 8.000 infecções humanas e 774 óbitos em 37 países, durante o período de 2002-2003. Os indivíduos infectados apresentaram sintomas de pneumonia com dano alveolar difuso que leva à Síndrome do Desconforto Respiratório Agudo (SDRA). Em 2012, o MERS-CoV surgiu na Arábia Saudita e foi responsável pela infecção de mais de 2.428 indivíduos, causando entorno de 838 óbitos ${ }^{11,12}$.

Oito anos depois, em 31 de dezembro de 2019, o início de um novo surto envolvendo um vírus da linhagem dos CoVs foi relatado. Os primeiros casos da infecção estão relacionados com pessoas com um quadro de pneumonia que frequentaram o mercado atacadista de frutos do mar em Wuhan, na China. No dia seguinte, 1으 de janeiro 2020, o mercado de Wuhan foi fechado. O Centro de Controle e Prevenção de Doenças Chinês (CDC) rapidamente iniciou um processo de investigação epidemiológica para identificar o patógeno causador da doença ${ }^{11}$.

Para esse fim, três pacientes adultos com pneumonia grave, admitidos no hospital de Wuhan foram selecionados. O RNA foi extraído do fluido broncoalveolar desses pacientes e usado como modelo para clonagem, sequenciando de genoma combinado. No dia 5 de janeiro de 2020, as leituras virais revelaram compatibilidade com a linhagem dos CoVs do gênero betacoronavírus ${ }^{13}$. Contudo, a origem zoonótica do vírus continua sendo investigada; entretanto, acredita-se que o morcego seja o provável reservatório primário do vírus, pois, com o reaparecimento dessa nova classe, vários estudos foram realizados e revelaram que o SARS-CoV-2 é $96 \%$ idêntico ao genoma de um CoVs causado pelo morcego ${ }^{14}$.

\section{Epidemiologia}

Após o início do surto de COVID-19, no final de 2019, uma série de casos se espalhou de Wuhan para toda a província de Hubei, na China. O primeiro caso exportado foi para a Tailândia em 3 de janeiro de 2020. Em 6 de fevereiro de 2020, um total de 28.276 casos foi confirmado com 565 mortes, envolvendo,

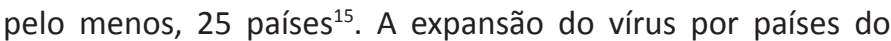
continente asiático, Europa, África, América e Oceania fez que a OMS declarasse pandemia global de COVID-19 em 11 de março de $2020^{16,17}$.

O primeiro caso na América Latina foi registrado no Brasil, em 26 de fevereiro de 2020. Foi identificado que o paciente positivo esteve na em Lombardia, Itália ${ }^{15}$. Em 25 de março de 2020, 186 países já haviam confirmado casos do vírus. Três dias depois, em 28 de abril de 2020, os Estados Unidos, ultrapassaram 1.000.000 de casos de COVID-19, o país, até o momento, é o novo epicentro mundial da doença ${ }^{17}$. Em 22 de maio de 2020, o Brasil, tornou-se o segundo país mais afetado pela doença, ultrapassando a Rússia ${ }^{18}$. Os principais marcos da pandemia de COVID-19 estão representados como linha do tempo na figura 2.

Figura 2. Linha do tempo relacionada à disseminação da COVID-19.

31 dez, 2019

Surtos de pneumonia de causa desconhecida foram relatados na Wuhan, China.

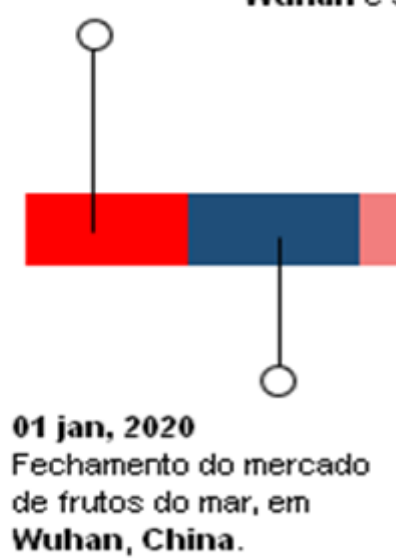

26 fev, 2020

Brasil reporta primeiro caso de COVID-19, em Säo Paulo.
28 abr, 2020 Estados Unidos ultrapassa 1 milhấo de casos de COVID-19.
05 jan, 2020 va cepa do coronavi foi isolada de pacientes em
03 jan, 2020

Disseminaçẫo do vírus para outros países.

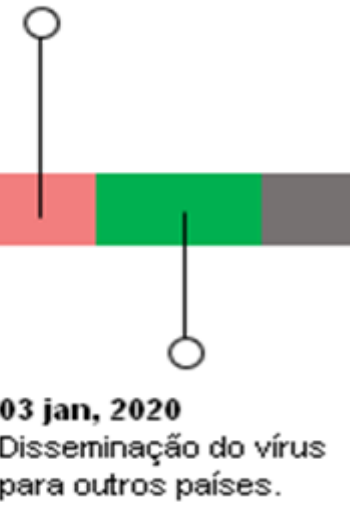

Wuhan, China.

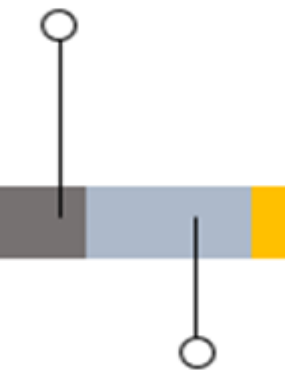

11 mar, 2020 OMS declara pandernia de COVID-19.

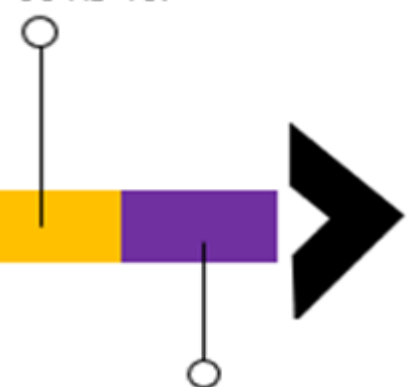

22 maio, 2020

Brasil se torna o segundo país mais afetado pela COVID-19.

Fonte: Autoria própria. 
Até a data de 16.6.2020, os dados obtidos pela OMS indicam que os países com o maior número de casos de COVID-19 são Estados Unidos (2.079.592), Brasil (867.624), Rússia (545.458), Reino Unido (296.861) e Espanha (244.109). Os países com maiores taxas de mortalidade, até hoje, são os Estados Unidos (115.484), Brasil (43.332), Reino Unido (41.736), Itália (34.371) e França (29.373). O Brasil já é o segundo país com maior número de casos no mundo, e segundo nas américas, com uma taxa de letalidade de $4,9 \%$ até o momento. No país, para o mesmo dia, foram notificados 17.110 novos casos, 612 novos óbitos relatados e 441.729 indivíduos que estão recuperados ${ }^{4,18}$.

A taxa de mortalidade da COVID-19 é estimada entre 1 e $3 \%$ dos pacientes sintomáticos. A mortalidade aumenta significativamente em pacientes adultos com idade $\geq 60$ anos, com comorbidades preexistentes como pneumonite crônica, obesidade, pressão alta, diabetes, câncer e insuficiência cardíaca ou renal ${ }^{16}$. Nesse sentido, a taxa de mortalidade é estimada em, aproximadamente, $14 \%$ em pacientes acima de 80 anos versus $0,2 \%$ entre os pacientes com menos de 40 anos $^{16}$.

\section{Morfologia}

Em 1965, por meio de microscopia eletrônica, foi possível observar as projeções na superfície do CoVs, que possuía forma semelhante a uma coroa solar (latim: corona $=$ coroa $)^{19}$. Esses vírus possuem tamanho minúsculo (65-125 nm de diâmetro) e contêm RNA (ácido ribonucleico) de fita simples com sentido positivo, com tamanho variando de 26 a 32 kilobases de comprimento ${ }^{12,14,20}$.

O SARS-CoV-2, agente causador da COVID-19, pertence à família coronoviridae ${ }^{23}$. Os CoVs possuem quatro subfamílias nomeadas de alfa, beta, gama e deltacoronavírus. Enquanto o alfa e betacoronavírus são, aparentemente, originários de mamíferos, em particular de morcegos, o vírus gama e delta são oriundos de porcos e pássaros ${ }^{9,6,21}$.

A sequência genética de SARS-CoV-2 é $\geq 70 \%$ semelhante à SARS-CoV. Logo o SARS-CoV-2 é capaz de usar o mesmo receptor de entrada de células, a Enzima Conversora de Angiotensina 2 (ACE2) que SARS-CoV para infectar os seres humanos ${ }^{22}$. Cabe, ainda, destacar as quatro principais proteínas estruturais que codificam o vírus: a proteína spike “espigão" (S), a glicoproteína de membrana (M), a proteína do nucleocapsídeo $(N)$ e a proteína de envelope (E). Essas proteínas desempenham um papel principal na entrada e replicação do vírus na célula hospedeira do CoVs22,23 (figura 3$)^{20}$.

Figura 3. Representação gráfica do SARS-CoV-2 destacando suas principais estruturas virais.

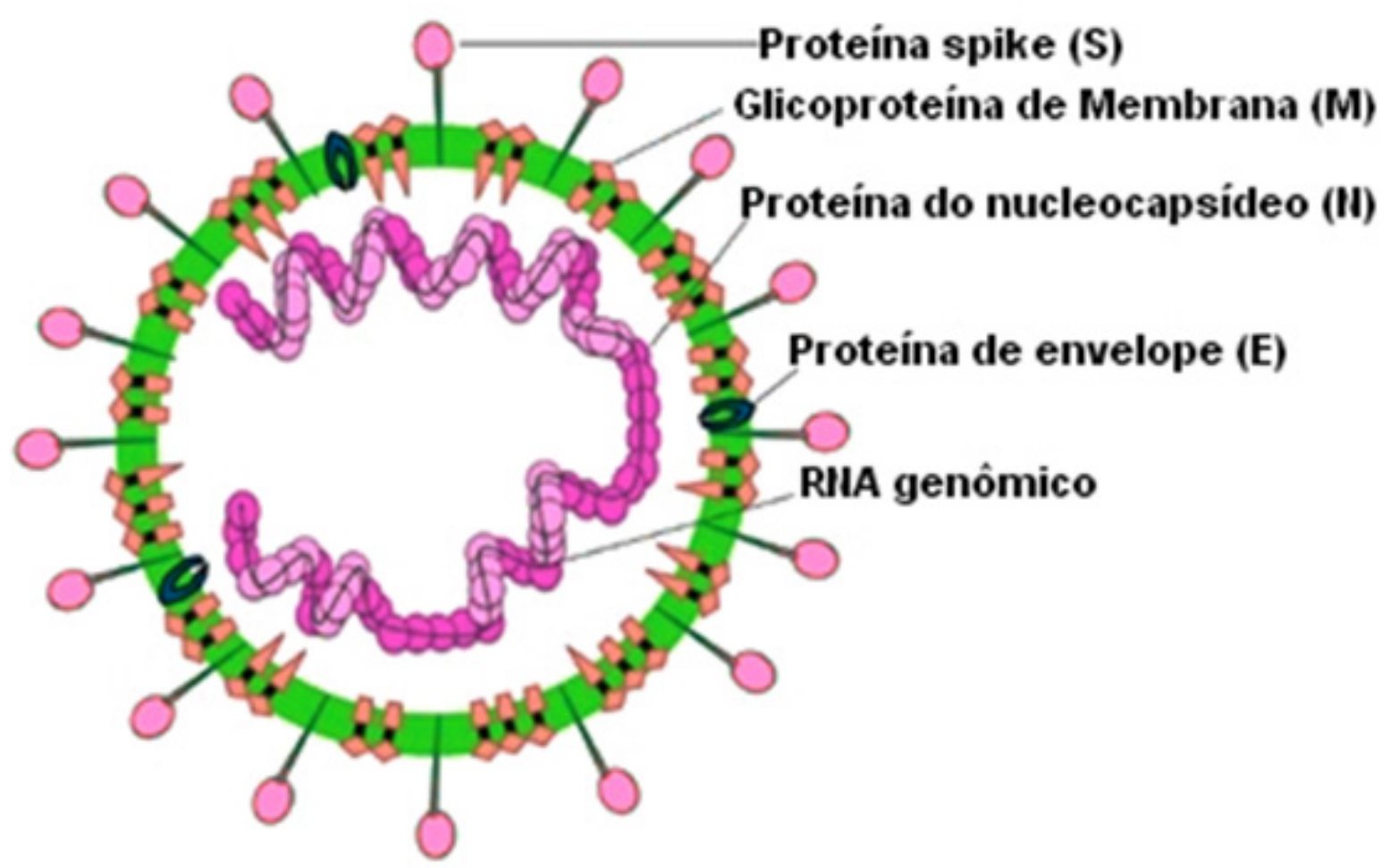

Legenda: Proteína spike (S), Glicoproteína de membrana (M), Proteína do nucleocapsídeo (N) e Proteína de envelope (E) e, o virião que possui uma nucleocápside composto de RNA genômico (+)ssRNA.

Fonte: Li e Colaboradores ${ }^{20}$. 
Transmissão e período de incubação

A transmissão do vírus ocorre de pessoa para pessoa, gota a gota (> $5 \mu \mathrm{g})$, mediante tosse, espirro ou fala. É importante destacar que a transmissão já pode ocorrer durante o período de incubação ou com indivíduos infectados, porém assintomáticos ${ }^{19,24}$. Também pode ocorrer a transmissão por aerossóis em pacientes submetidos a procedimentos de vias aéreas, como a intubação orotraqueal ou aspiração de vias aéreas ${ }^{21}$. Até o momento, a transmissão transplacentária de gestantes para seu feto não foi descrita ${ }^{25}$.

Deve-se atentar que o agente pode permanecer viável e infeccioso em aerossóis, por até três horas e em superfícies contaminadas (e.g., vidros, metais, tecidos, alimentos, etc.) por até três dias ${ }^{7}$. O período de incubação do vírus varia de 2 a 14 dias (em média 5 dias) ${ }^{25,26}$.

\section{Manifestações clínicas}

Segundo Ciotti e Colaboradores ${ }^{21}$, os pacientes infectados com SARS-CoV-2 podem apresentar uma ampla gama de sintomas que variam de leve a grave, que podem levar à morte, ou até mesmo, permanecer assintomáticos, e possui como principal característica a alta transmissibilidade. Os sintomas geralmente aparecem 2-14 dias após a exposição viral, e os sintomas mais comuns relatados em $31-83 \%$ dos pacientes, incluem febre, tosse seca e falta de ar.

Foi relatado que cerca de 2 a 10\% dos pacientes com COVID-19 apresentavam sintomas gastrointestinais como náuseas, vômitos, diarreia e dor abdominal. O vírus também pode causar sintomas como dor de garganta, tremor, confusão, dor de cabeça, mialgia e dispneia ${ }^{26}$. O quadro pode progredir para hipoxemia (insuficiência de oxigênio no sangue), dificuldade em respirar e SDRA. Pacientes nesta fase podem necessitar de ventilação em Unidade de Terapia Intensiva (UTI) ${ }^{5}$.

\section{Diagnóstico}

O diagnóstico de COVID-19 tem sido realizado por meio da observação dos sintomas. Contudo, o método de diagnóstico de escolha é a detecção genômica do vírus por um método de biologia molecular, a Reação em Cadeia da Polimerase Via Transcriptase Reversa (RT-PCR), em material colhido da nasofaringe ou da orofaringe ${ }^{11}$.

No entanto, se esse teste for negativo e a suspeita clínica for alta, a recomendação é de que ele seja realizado novamente, inclusive, em material obtido de outros sítios respiratórios. A resposta imune ao vírus pode ser detectada pelos testes rápidos de IgM, imediatamente, após a janela imunológica (3-6 dias), e IgG, mais tardiamente (oito dias) ${ }^{27}$.

Esses métodos são complementares a RT-PCR na medida em que permitem diagnosticar infecções em um estágio posterior, no momento em que o vírus não esteja mais presente na nasofaringe, o que seria interessante para testar uma possível mudança no tropismo viral para o trato digestivo e excreção através das fezes ${ }^{16,28}$.

\section{Tratamento}

Atualmente, não há uma vacina e medicamentos específicos contra a COVID-19. Contudo, existem vários fármacos disponíveis no mercado em uso off-label (medicamento que é usado para uma finalidade diferente daquela para a qual foi originalmente destinado), com a proposta de inibir a entrada do vírus na célula hospedeira e levar à excreção vira|29,30.

Dessa maneira, estão sendo utilizados como estratégias terapêuticas, os fármacos inibidores da enzima conversora da angiotensina e os bloqueadores dos receptores da angiotensina; os Anti-Inflamatórios Não Esteroidais (AINEs), como o paracetamol; os antiparasitários, como hidroxicloroquina (associado ou não à azitromicina), cloroquina, nitazoxanida e ivermectina; os antirretrovirais, como lopinavir/ritonavir; os análogos de nucleotídeos, como remdesivir; glicocorticoides e o plasma convalescente. Terapias nutricionais, como vitaminas $A, D$ e $C$ e o uso de zinco e selênio, também, estão sendo empregados $^{31}$.

Nos casos de sintomas iniciais, pode ser realizado o manejo com o uso de AINEs. Dessa forma, para tratar os sintomas de febre e dor de garganta, é recomendado o uso do paracetamol, devido ao perfil de segurança do fármaco ${ }^{16}$. Entretanto, há discussões quanto à utilização do ibuprofeno, fármaco que poderia deixar as células do pulmão mais vulneráveis, propiciando a multiplicação do vírus em pacientes diabéticos e hipertensos ${ }^{7}$.

Contudo, a OMS liberou o uso do ibuprofeno para pacientes com COVID-19, destacando que não há evidências científicas que comprovem tais efeitos negativos associados ao fármaco ${ }^{32}$. Publicações recentes têm chamado a atenção para o possível benefício da cloroquina e hidroxicloroquina em pacientes infectados com o SARS-CoV-2. Esses fármacos são considerados drogas seguras e com efeitos colaterais geralmente leves e transitórios. Entretanto, a margem entre a dose terapêutica e a dose tóxica é estreita, bem como o envenenamento com cloroquina tem sido associado a distúrbios cardiovasculares e retinopatia ${ }^{33}$.

A hidroxicloroquina, por exemplo, possui algumas contraindicações, tais como: a dose total diária não deve exceder 400mg, o fármaco não deve ser utilizado por mais de 5 anos, na existência de doença renal ou hepática concomitante, de doença retiniana ou maculopatia, e na idade $>60$ anos $^{34}$.

O remdesivir é uma pró-droga de um análogo de nucleotídeos, em desenvolvimento pela empresa biofarmacêutica Gilead Sciences. O fármaco é capaz de inibir a polimerase viral e que tem ação contra várias famílias de vírus, incluindo o ebola e os CoVs. Estudos in vitro já haviam mostrado a ação do fármaco contra SARS-CoV e MERS-CoV e, mais recentemente, contra SARS-COV- $2^{15}$.

Em um relato de caso sobre o primeiro caso de COVID-19 nos 
Estados Unidos, o remdesivir foi administrado, resultando na diminuição da carga viral em amostras nasofaríngeas e orofaríngeas, e a condição clínica do paciente foi melhorada. No entanto, ensaios clínicos randomizados são necessários para determinar a segurança e eficácia desse medicamento no tratamento de pacientes com o vírus ${ }^{15}$.

Hung e Colaboradores $^{35}$ realizaram um ensaio clínico randomizado controlado, fase 2, com 127 pacientes adultos com COVID-19 em Hong Kong, China. Esses pacientes receberam uma combinação tripla das substâncias interferon beta 1-b, lopinavirritonavir e ribavirin. 0 estudo demonstrou que a combinação eliminou o vírus em média 7 dias após o início do tratamento, tempo significativamente menor do que o grupo controle, que foi tratado somente com lopinavir-ritonavir e necessitou de 12 dias para que o vírus não pudesse mais ser detectado no teste molecular RT-PCR. Entretanto, os pacientes envolvidos tinham quadros leves e moderados da doença. Assim, apesar desses resultados animadores, é necessário confirmar em uma fase mais abrangente, a 3, que essa combinação de medicamentos é realmente eficaz em pacientes mais graves ${ }^{35}$.

Destaca-se ainda, que é preciso ter em mente que esses Quadro 1. Medidas de prevenção à exposição à COVID-19 medicamentos foram desenvolvidos para diferentes indicações, e não foram examinados para o tratamento da COVID-19; assim, deve a haver uma atenção especial em torno de sua farmacologia clínica e estratégias de dosagem, observando que os esquemas posológicos dos medicamentos existentes foram desenvolvidos para diferentes indicações. E, para o acerto da dose, requer um conhecimento potencial da farmacocinética e cinética viral dessas medicações para realizar e orientar o seu uso racional ${ }^{36}$.

\section{Prevenção}

Como, neste momento, não há tratamentos aprovados para essa infecção, a prevenção é crucial. Várias propriedades desse vírus dificultam a prevenção, como a infecciosidade, mesmo antes do início dos sintomas no período de incubação, transmissão de pessoas assintomáticas, longo período de incubação, tropismo para superfícies mucosas como conjuntiva, duração prolongada da doença e transmissão mesmo após a recuperação clínica ${ }^{25}$. Para indivíduos com suspeita de COVID-19, é recomendado o uso de máscara cirúrgica e a permanência em isolamento. Para a população em geral, as seguintes recomendações foram emitidas para prevenir a exposição à COVID-19 (quadro 1) 1,13,37,38.

Lavar as mãos com água e sabão por, pelo menos, 20 segundos;
Higienizar as mãos com álcool em gel em concentrações superiores a 70\%;
Praticar etiqueta respiratória, que se refere à cobertura do nariz e boca com o cotovelo dobrado ou com um tecido quando
espirrar ou tossir, seguido pelo descarte de tecidos e higiene das mãos;
Manter uma distância de 1 metro das pessoas que estão com tosse, espirros ou febre;
Evitar tocar nos olhos, no nariz e na boca com as mãos não lavadas;
Limpar e desinfetar objetos e superfícies tocados com frequência (e. g., botões de elevador, corrimão, maçanetas de portas,
celulares, etc.);
Desinfetar os objetos e as superfícies tocados com frequência com álcool (62-71\%), peróxido de hidrogênio (0,5\%) ou
hipoclorito de sódio (0,1\%);
Procurar assistência médica se acreditar que foi exposto e apresenta sintomas como febre, tosse ou dificuldade respiratória;
Usar máscara;
Manter distanciamento e isolamento social.

Fonte: Garrido e Garrido ${ }^{7}$, Sifuentes-Rodríguez e Palacios-Reyes ${ }^{13}$, Graham e Colaboradores ${ }^{37}$, Garcia e Duarte ${ }^{38}$.

\section{CONSIDERAÇÕES FINAIS}

Constata-se, na atualidade, que a pandemia de COVID-19 já se configura como o maior desafio para saúde pública do século $\mathrm{XXI}$, com elevadas taxas de morbidade e mortalidade em todo o mundo, o que requer medidas rápidas e conscientes para preservar à população. E como a produção de uma vacina e de medicamentos para doença ainda está distante, a única forma de controle do curso da doença até o momento, são medidas por meio da prevenção e restrição do contato interpessoal.

Diante dos aspectos apresentados neste artigo, pode-se afirmar que a origem do SARS-CoV-2, agente causador da COVID-19, ainda não foi totalmente elucidada. Sabe-se que a infecção pode causar complicações mais severas em populações de risco e com mais de 60 anos, sendo, provavelmente, mais letal. A infectividade do SARS-CoV-2 é maior em comparação com SARSCoV e MERS-CoV, principalmente por se tratar do primeiro vírus da família dos CoVs capaz de ser transmitido de pessoa para pessoa.

Os resultados das pesquisas, até o momento, são promissores e alguns chamam atenção, uma vez que incluem fármacos (em o uso off label) que já estão à disposição no mercado, e suas ações no organismo humano são conhecidas. Entretanto, não há ainda um entendimento sobre qual fármaco seria realmente eficaz, devido à falta de evidências científicas conclusivas, o que 
tem gerado incertezas nos procedimentos de decisão clínica. Em vista disso, espera-se que, futuramente, sejam realizados mais ensaios clínicos randomizados, envolvendo um maior número de pacientes, para que seja possível elucidar a efetividade e segurança desses medicamentos no combate à COVID-19.

\section{AGRADECIMENTOS}

O presente trabalho foi realizado com apoio da Coordenação de Aperfeiçoamento de Pessoal de Nível Superior - Brasil (CAPES) - Código de Financiamento 001.

\section{REFERÊNCIAS}

1. Chen ATC, Moniz CMV, Ribeiro-Júnior U, et al. How should health systems prepare for the evolving COVID-19 pandemic? Reflections from the perspective of a Tertiary Cancer Center. Clinics 2020; Abr; 75: 1-3. doi: https://doi. org/10.6061/clinics/2020/e1864.

2. Croda JHR, Garcia LP. Resposta imediata da Vigilância em Saúde à epidemia da COVID-19. Epidemiol. Serv. Saúde 2020 Mar; 29(1): 1-3. doi: https://doi. org/10.5123/s1679-49742020000100021.

3. Strabelli TMV, Uip DE. COVID-19 and the Heart. Arq Bras Cardiol. 2020 Abr; 114(4): 598-600. doi: 10.36660/abc.20200209.

4. World Health Organization. Novel Coronavirus (2019-nCoV; COVID-19). Situation Report - 148 [Internet]. Genebra: WHO; 2020 Jun 16 [acesso 2020 Jun 16]. Disponível em: https://www.who.int/docs/default-source/coronaviruse/ situation-reports/20200616-covid-19-sitrep-148-draft.pdf?sfvrsn=9b2015e9_2.

5. Kannan S, Shaik Syed Ali P, Sheeza A, et al. COVID-19 (Novel Coronavirus 2019) - recent trends. Eur Rev Med Pharmacol Sci 2020; 24: 2006-2011. doi: 10.26355/eurrev_202002_20378.

6. Lima, DLF, DIAS, AA, Rabelo, RS, Cruz, ID, Costa, SC, Nigri, FMN, et al. COVID-19 no Estado do Ceará: Comportamentos e crenças na chegada da pandemia. Cien Saude Colet [internet]. 2020 Maio [acesso 2020 Maio 11]. 25(5): 1575-1586. Disponível em: http://www.cienciaesaudecoletiva.com.br/artigos/covid19-noestado-do-ceara-comportamentos-e-crencas-na-chegada-da-pandemia/17540. doi: https://doi.org/10.1590/1413-81232020255.07192020.

7. Garrido RG, Garrido FSRG. COVID-19: Um panorama com ênfase em medidas restritivas de contato interpessoal. Interf. Cient. 2020; 8: 127-141. doi: 10.17564/2316-3798.2020v8n2.

8. Lugoboni LF, Santos BDS, Machado EC, Gomes JL. Modelos de gestão: uma revisão da literatura brasileira. CAFI - Contab Atuária, Finanças Informação 2020; 3: 83-102. doi: https://doi.org/10.23925/cafi.v3i1.45651.

9. Velavan TP, Meyer CG. The COVID-19 epidemic. Trop Med Int Heal [Internet]. $2020 \mathrm{Fev}$ [acesso 2020 Maio 11]; 25: 278-280. Disponível em: https:// onlinelibrary.wiley.com/doi/abs/10.1111/tmi.13383.

10. Gralinski LE, Menachery VD. Return of the Coronavirus: 2019-nCoV. Viruses [Internet] 2020 Jan [acesso 2020 Maio 12]; 12(2):135. Disponível em: https:// www.mdpi.com/1999-4915/12/2/135.

11. Lu R, Zhao X, Li J, Niu P, Yang B, Wu H, et al. Genomic characterisation and epidemiology of 2019 novel coronavirus: implications for virus origins and receptor binding. Lancet 2020 Fev; 395(10224): 565-574. doi: https://doi. org/10.1016/S0140-6736(20)30251-8.

12. Shereen MA, Khan S, Kazmi A, Kazmi A, Bashir N, Siddique R. COVID-19 infection: Origin, transmission, and characteristics of human coronaviruses. J Adv Res. 2020 Jul; 24: 91-98. doi: https://doi.org/10.1016/j.jare.2020.03.005.

13. Sifuentes-Rodríguez E, Palacios-Reyes D. Covid-19: The outbreak caused by a new coronavirus. Bol Med Hosp Infant Mex. 2020; 77(2): 47-53. doi: 10.24875/ BMHIM.20000039.

14. Cruz MP, Santos E, Cervantes MAV, et al. COVID-19, a worldwide public health emergency. Rev. Clin. Esp. 2020 Mar; S0014-2565(20): 30092-8. doi: 10.1016/j.rce.2020.03.001
15. Wu Y-C, Chen C-S, Chan Y-J. The Outbreak of COVID-19: An Overview. Chin Med J 2020 Mar; 83: 217-220. doi: 10.1097/JCMA.0000000000000270.

16. Davenne E, Giot JB, Huynen P. Coronavirus et COVID-19 : le point sur une pandémie galopante. Rev Med Liege. 2020 Abr; 75(4): 218-225.

17. Manrique-Abril FG, Agudelo-Calderon CA, González-Chordá VM, et al. SIR model of the COVID-19 pandemic in Colombia. Rev salud pública 2020 Jan-Fev 22(1): 1-9. doi: http://dx.doi.org/10.15446/rsap.v22.85977.

18. Ministério da Saúde (BR). Coronavírus Brasil. Painel: Coronavírus [Internet]. 2020 [acesso 2020 Jun 16]. Disponível em: https://covid.saude.gov.br/.

19. Reis-Filho JA, Quinto D. COVID-19, social isolation, artisanal fishery and food security: How these issues are related and how important is the sovereignty of fishing workers in the face of the dystopian scenario. SciELO 2020. doi: https:// doi.org/10.1590/SciELOPreprints.54.Preprint 2020.

20. Li G, Fan Y, Lai Y, Han T, Li Z, Zhou P, et al. Coronavirus infections and immune responses. J Med Virol. 2020 Abr; 92(4): 424-432. Disponível em: https:// onlinelibrary.wiley.com/doi/abs/10.1002/jmv.25685.

21. Ciotti $M$, Angeletti $S$, Minieri $M$, Giovannetti $M$, Benvenuto $D$, Pascarella S, et al. COVID-19 Outbreak: An Overview. Chemotherapy 2020 Abr; 1-7. doi: $10.1159 / 000507423$

22. Li H, Liu SM, Yu XH, Tang S-L, Tang C-K. Coronavirus disease 2019 (COVID-19): current status and future perspectives. Int J Antimicrob Agents 2020 Maio; 55(5): 105951. doi: 10.1016/j.jjantimicag.2020.105951. Preprint 2020.

23. Shanmugaraj B, Siriwattananon K, Wangkanont K, Phoolcharoen W. Perspectives on monoclonal antibody therapy as potential therapeutic intervention for Coronavirus disease-19 (COVID-19). Asian Pac J Allergy Immunol. 2020 Mar; 38(1): 10-18. doi:10.12932/AP-200220-0773.

24. Ministério da Saúde (BR). Secretaria de Atenção Especializada à Saúde. Departamento de Atenção Hospitalar, Domiciliar e de Urgência. Protocolo de manejo clínico da Covid-19 na Atenção Especializada [Internet]. Brasília: Ministério da Saúde; 2020 [acesso 2020 Abr 25]. Disponível em: https:// portaldeboaspraticas.iff.fiocruz.br/ate.

25. Singhal T. A Review of Coronavirus Disease-2019 (COVID-19). Indian J Pediatr. 2020; 87(4): 281-286. doi: 10.1007/s12098-020-03263-6.

26. Ozma MA, Maroufi P, Khodadadi E, Kose S, Esposito I, Ganbarov K, et al. Clinical Manifestation, Diagnosis, Prevention and Control of SARS-CoV-2 (COVID-19) During the Outbreak Period. Infez Med. 2020 [acesso 2020 Abr 25]. Disponível em: https://pubmed.ncbi.nlm.nih.gov/32275257/ Ahead of print.

27. Chate RC, Fonseca EKUN, Passos RBD, Teles GBS, Shoji H, Szarf G. Apresentação tomográfica da infecção pulmonar na COVID-19: experiência brasileira inicial. J Bras Pneumol 2020 Abr; 46(2): 1-4. Disponível em: http:// www.jornaldepneumologia.com.br/detalhe_artigo.asp?id=3339.

28. Lima DS, Leite JAD Filho, Gurgel MVSA, Aguiar AF Neto, Costa EFM, Maia FXF Filho, et al. Recomendações para cirurgia de emergência durante a pandemia do COVID-19. J Health Biol Sci. 2020 J; 8(1):1-3.

29. Ribeiro TB, Mazotti TA, Nobre MRC, Stein A, Melo DO. Os estudos brasileiros de intervenção em andamento para o COVID-19: protocolos de ensaios clínicos. 
SciELO 2020. doi: 10.1590/SciELOPreprints.45. Preprint 2020.

30. Wang M, Cao R, Zhang L, Xinglou Y, Liu J, Xu M, et al. Remdesivir and chloroquine effectively inhibit the recently emerged novel coronavirus (2019nCoV) in vitro. Cell Res. 2020 Mar; 30(3): 269-271. doi: 10.1038/s41422-0200282-0.

31. Mota DM, Kuchenbecker RDS. Considerações sobre o uso de evidências científicas em tempos de pandemia: o caso da Covid-19. Visa em Debate. 2020 Maio; 8(2). doi: 10.22239/2317-269x.01541.Preprint 2020.

32. Ribeiro W. OMS volta atrás sobre restrição de ibuprofeno no tratamento do coronavírus. São Paulo: ICQT; 2020 [acesso 2020 Abr 27]. Disponível em:https:// www.ictq.com.br/farmacia-clinica/1288-oms-volta-atras-sobre-restricao-deibuprofeno-no-tratamento-do-coronavirus.

33. Touret F, Lamballerie $X$ de. Of chloroquine and COVID-19. Antiviral Res. . 2020 Maio; 177: 104762. doi: 10.1016/j.antiviral.2020.104762. Preprint 2020.

34. Menezes CR, Sanches C, Chequer FMD. Efetividade e toxicidade da cloroquina e da hidroxicloroquina associada (ou não) à azitromicina para tratamento da COVID-19. O que sabemos até o momento? J Heal Biol Sci 2020; 8(1): 1-9. doi: http://dx.doi.org/10.12662/2317-3076jhbs.v8i1.3206.p1-9.2020.

35. Hung IF-N, Lung K-C, Tso EY-K, Liu R, Chung TW-H, Chu M-Y, et al. Triple combination of interferon beta-1b, lopinavir-ritonavir, and ribavirin in the treatment of patients admitted to hospital with COVID-19: an open-label, randomised, phase 2 trial. Lancet. 2020 Maio [acesso 2020 Maio 8]. 395(10238): 1695-1704. doi: https://doi.org/10.1016/S0140-6736(20)31042-4.

36. Smith PF, Dodds M, Bentley D, Yei K, Rayner C. Dosing will be a key success factor in repurposing antivirals for COVID-19. Br J Clin Pharmacol. 2020 Abr. doi: 10.1111/bcp.14314. Preprint 2020.

37. Graham WC, Cruz CS Dela, Cao B, Pasnick S, Shazia J. Novel Wuhan (2019NCoV) coronavirus. Am J Respir Crit Care Med 2020 Fev; 201(4): 7-8. doi: 10.1164/rccm.2014P7.

38. Garcia LP, Duarte E. Intervenções não farmacológicas para o enfrentamento à epidemia da COVID-19 no Brasil. Epidemiol. Serv. Saúde 2020; 29(2): 1-4.

\section{Como citar este artigo/How to cite this article:}

Pereira MD, Pereira MD, Costa CFT, Santos CKA, Dantas EHM. Aspectos epidemiológicos, clínicos e terapêuticos da Doença de Coronavírus 2019 (COVID-19). J Health Biol Sci. 2020 J; 8(1):1-8. 